\title{
Small Cell Carcinoma of the Ovary (Hypercalcemic Type): Malignant Rhabdoid Tumor
}

\author{
Peter Kascak $^{\mathrm{a}, \mathrm{b}} \quad$ Michal Zamecnik $^{\mathrm{c}, \mathrm{d}}$ Branislav Bystricky $^{\mathrm{e}}$ \\ ${ }^{a}$ Department of Obstetrics and Gynecology, Faculty Hospital, Trenčín, Slovakia; ${ }^{b}$ Faculty of \\ Health, Alexander Dubcek University, Trenčín, Slovakia; ' Medirex Group Academy n.o., \\ Bratislava, Slovakia; ${ }^{d}$ Department of Pathology, Agel Laboratories, Nový Jičín, \\ Czech Republic; ${ }^{e}$ Department of Oncology, Faculty Hospital, Trenčín, Slovakia
}

\section{Keywords}

Ovarian cancer · Small cell carcinoma of hypercalcemic type · Chemotherapy · Immunohistochemistry · Malignant rhabdoid tumor

\begin{abstract}
We present a rare case of malignant rhabdoid tumor (ovarian small cell carcinoma of hypercalcemic type) in a 24-year-old female with fulminant course. Clinically, hypercalcemia was not found at the time of primary diagnosis. However, it appeared later during the course of tumor progression. Histologically, the tumor showed classical features of small cell carcinoma of hypercalcemic type. Therapy included radical surgery with adjuvant chemotherapy. Despite this intensive therapy, the disease recurred and the patient died 10 months after the diagnosis. We discuss the diagnosis and therapy of this tumor, as well as its recent classification as malignant rhabdoid tumor.

\section{Introduction}

Small cell carcinoma of the ovary of hypercalcemic type (SCCOHT) is a very rare tumor usually found in young females. Hypercalcemia is found in the majority of cases. It is a highly malignant tumor with a poor prognosis [1-3]. Based on a similar genetic profile to malignant 
Kascak et al.: Small Cell Carcinoma of the Ovary (Hypercalcemic Type): Malignant Rhabdoid Tumor

rhabdoid tumors, it was suggested to use the term 'malignant rhabdoid tumor of the ovary' $[4,5]$. Herein, we present a recent case of this rare entity from our practice and discuss its differential diagnosis and management.

\section{Case Presentation}

A 24-year-old female was referred by her community-based gynecologist with abdominal pain lasting for over 3 weeks and a feeling of bloatedness. On physical examination, she appeared fit and well, without any distress. Her background medical history was unremarkable, and she was nulliparous. Abdominal palpation revealed a mass up to $10 \mathrm{~cm}$ above her umbilicus. Diagnostic ultrasound confirmed an isoechogenic, nonhomogeneous, rounded solid and cystic mass of $20 \mathrm{~cm}$ in diameter. Slight elevation of liver enzymes and blood urea nitrogen was detected; otherwise, blood tests were within normal limits. The tumor marker Ca125 was elevated at $59.5 \mathrm{kIU} / \mathrm{l}$ [upper limit of normal (ULN): $35 \mathrm{kIU} / \mathrm{l}$ ], HE4 at 201.8 pmol/l (premenopausal ULN: 70 pmol/l), and the corresponding ROMA (Risk of Ovarian Malignancy Algorithm) index was $70.77 \%$. The patient was admitted to our hospital for further imaging and treatment. Contrast-enhanced CT examination demonstrated a cystic tumor with some solid components arising from the right ovary. The tumor measured $20 \mathrm{~cm}$ in diameter; there was a minimal amount of free fluid. There were no other pathological findings on CT examination (fig. 1). During diagnostic laparotomy, we found a large tumor mass filling the true pelvis and abdominal cavity up to and above the umbilicus. The tumor had a soft consistency, with rupturing small cystic cavities. It arose from the right ovary and was twisted on a thick stalk. The rest of the abdominal cavity was negative for metastatic spread. The tumor was completely resected and sent for histopathological examination.

Grossly, the tumor measured $16 \mathrm{~cm}$ (after formalin fixation), and it showed a soft consistency, an incomplete and thin pseudocapsule, and gray-to-yellowish cut surface with necrosis and hemorrhages. Histologically (fig. 2), it was composed of small cells with high nuclear atypia and numerous mitoses. Nucleoli were not prominent, and the cytoplasm was scanty. The cell population was solid, with follicle-like spaces and with some areas showing a trabecular pattern. The tumor cells focally penetrated the fibrous pseudocapsule, and rare foci of the vascular invasion were seen. Immunohistochemically, the tumor was diffusely positive for p53 and WT1 (see online suppl. A; for all online suppl. material, see www.karger.com/doi/10.1159/000446694). Focal expression was found for pancytokeratin AE1/AE3, epithelial membrane antigen (online suppl. B), vimentin, CD99, INI1, and CD10. The following antibodies gave negative results: estrogen and progesterone receptors, $\alpha-$ inhibin, calretinin, OCT3/4, c-kit, placental alkaline phosphatase, leukocyte common antigen, S-100 protein, HMB45, melan A, chromogranin A, CD56, synaptophysin, $\alpha$-smooth muscle actin, desmin, h-caldesmon, Fli-1, and neurofilament protein. Histological and immunohistochemical features led to the diagnosis of SCCOHT. This case was discussed at the weekly oncology multidisciplinary meeting. It was decided to perform a radical oncological staging procedure, but to leave the uterus, for possible future pregnancy through oocyte donation. A second laparotomy was performed within 2 weeks of the first operation. The findings on the patient's ovaries, greater omentum, appendix, peritoneal biopsies, 15 and 24 paraaortic and pelvic lymph nodes, respectively, were all without malignancy. At this stage, $400 \mathrm{ml}$ of ascites was detected, which was cytologically negative for tumor cells. After uneventful recovery, she underwent 4 cycles of adjuvant chemotherapy with cisplatin and etoposide. During this time, the patient's calcium and tumor markers (Ca125 and NSE) were within normal limits. 


\section{Case Reports in Oncology}

A CT scan at completion of the adjuvant chemotherapy was without any recurrence. Four months after the final cycle of adjuvant chemotherapy, the patient was stared on hormone replacement treatment. Five months after completion of the adjuvant chemotherapy, she presented with anorexia, generalized weakness, nausea, and constipation. During physical examination, deep palpation in her right hypogastric region revealed a poorly defined, nontender mass. Transabdominal and transvaginal ultrasound confirmed an $8-\mathrm{cm}$ mass at the right ovarian fossa. A staging CT scan revealed 2 tumors in the abdominal cavity: the first was placed above the aortic bifurcation with a dimension of $81 \times 47 \times 106 \mathrm{~mm}(\mathrm{AP} \times \mathrm{LL} \times$ $\mathrm{CC}$ ) and causing compression of the inferior vena cava and the surrounding structures; the second one was in the true pelvis measuring $95 \times 66 \times 60 \mathrm{~mm}$ (fig. 3). At this stage, malignant hypercalcemia was detected with a blood calcium of $5.26 \mathrm{mmol} / \mathrm{l}$ (ULN: $2.7 \mathrm{mmol} / \mathrm{l}$ ) and with corresponding shortening of the QT interval $(240 \mathrm{~ms})$ on ECG. The tumor marker Ca125 was negative, but NSE rose above the ULN. Chest X-ray and MRI of the brain were without metastases. Because of early relapse after curative treatment, further surgical intervention was not pursued. Associated hypercalcemia was managed with forced diuresis and intravenous bisphosphonates. Palliative chemotherapy with carboplatin and etoposide (due to renal failure) was commenced. After the second cycle of this palliative treatment, she was urgently operated for ileus. During this third surgery, the 2 tumor masses were visualized: the first was retrocecal, and the second one filled the whole true pelvis with infiltration of the urinary bladder. Only palliative sigmoidostomy was possible at this stage. As this event signified disease progression, a change of chemotherapy was planned. Unfortunately, the patient died on the 4th postoperative day with signs of massive pulmonary embolism (10 months after initial surgery). No autopsy was performed.

\section{Discussion}

The clinical signs of our case as well as the pathological findings confirmed SCCOHT. This rare tumor entity was first fully described by Dickersin et al. [2] in 1982. Before this, it was briefly mentioned in a 1979 monograph by Scully [6]. After these publications, further case reports and series followed. Currently, there are around 300 cases of SCCOHT described in the literature [7]. The clinical picture of SCCOHT includes young age, with a median of 2428 years, hypercalcemia in two thirds of cases, and a stage higher than I in $75 \%$ of patients [1]. Tumor markers, useful in epithelial ovarian cancers, are noninformative in SCCOHT. Hypercalcemia in a young female with adnexal mass is pathognomonic of SCCOHT. Our young female patient had initial normocalcemia, and the tumor markers were nonspecifically raised. The histological diagnosis of SCCOHT is based on the finding of a small cell population with high nuclear atypia, numerous mitoses, and frequent necrosis. The growth pattern is usually solid and trabecular, with typical and almost pathognomic follicle-like spaces. In addition, some unusual findings have been described, such as mucinous glands, mucinous signet ring cells, spindle cell sarcomatoid change, large cells, and rhabdoid cytomorphology $[1,3]$. Immunohistochemically, SCCOHTs are positive for vimentin, and they show a focal expression of epithelial markers. BRG1 protein, a product of the SMARCA4 gene, is absent almost constantly [5]. In addition, expressions of p53, CD56, WT1, calretinin, CD10, 'parathyroid-related' polypeptide, and $\alpha$-smooth muscle actin were described $[3,8]$. In cases with rhabdoid cytomorphology, the tumors were very similar to the so-called malignant rhabdoid tumor [9]. Molecular genetic studies showed that occasional rhabdoid morphology is quite in accordance with genetic changes. SCCOHTs contain alterations in genes SMARCB1 or 
SMARCA4, which are frequent also in malignant rhabdoid tumors [4]. Therefore, some authors propose to rename SCCOHT as 'malignant rhabdoid tumor of the ovary' [4, 5]. This view is supported by the following features shared by both SCCOHT and malignant rhabdoid tumor: occasional familial occurrence, frequent hypercalcemia, and immunohistochemical polyphenotypia $[3,4,8]$. It remains, however, to explain some findings which are not typical for rhabdoid tumor, such as mucinous glands, the common absence of rhabdoid cells, and findings of SMARC4 alterations in some neoplasms unrelated to rhabdoid tumor (pulmonary and pancreatic carcinomas, endometrioid carcinomas) [10, 11]. Treatment of SCCOHT is stage dependent. In early stages, radical surgery - as in epithelial high-grade ovarian cancers - is advised. Adjuvant chemotherapy with cisplatin and etoposide usually follows; some authors also recommend external beam radiotherapy [12]. This treatment scheme is commonly employed in small cell lung cancer and in small cell cancers generally. Most patients with SCCOHT respond to chemotherapy treatment employing a combination of agents, such as cisplatin, etoposide, doxorubicin, bleomycin or cyclophosphamide and vinblastine. There are different views on a radical approach in early stages. Some authors recommend fertilitysparing surgery followed by adjuvant chemotherapy, others suggest radical staging surgery with pelvic and paraaortic lymphadenectomy $[13,14]$. For advanced stages, neoadjuvant chemotherapy, followed by radical staging surgery is recommended [12]. Due to the highly aggressive nature of this tumor, prognosis is very poor. Only a third of early-stage patients have the benefit of a long relapse-free interval. These patients are usually older than 30 years, have normal blood calcium, their tumor mass is $<10 \mathrm{~cm}$ without large cells on pathology, and they underwent radical staging procedure [1]. In advanced cases, aggressive surgical management, combined with chemotherapy with or without radiotherapy is based only on case reports $[2,15]$. Despite various radical approaches, the 1-year survival of SCCOHT patients is only around $50 \%$, similar to the case presented above. In the face of these poor results and high morbidity, an aggressive approach to the treatment of SCCOHT remains questionable.

\section{Conclusions}

We presented a rare case of SCCOHT/malignant rhabdoid tumor of the ovary. The clinical and histopathological findings were similar to other reported cases. Unfortunately, our patient died 10 months after diagnosis, highlighting the highly malignant nature of this tumor.

\section{Acknowledgment}

The authors acknowledge the support provided by the Operational Program Research and Development building additional technical infrastructure for the research of diagnostic procedures and methodology in early diagnostics of the most frequent oncological diseases in women, project ITMS 26210120026, with financial assistance from the European Regional Development Fund. 
Kascak et al.: Small Cell Carcinoma of the Ovary (Hypercalcemic Type): Malignant Rhabdoid Tumor

\section{Statement of Ethics}

Consent for publication of this case report was obtained from the next of kin of the deceased patient.

\section{Disclosure Statement}

None of the authors have any relevant financial or nonfinancial relationships to disclose.

\section{References}

1 Young RH, Oliva E, Scully RE: Small cell carcinoma of the ovary, hypercalcemic type. A clinicopathological analysis of 150 cases. Am J Surg Pathol 1994;18:1102-1116.

-2 Dickersin GR, Kline IW, Scully RE: Small cell carcinoma of the ovary with hypercalcemia: a report of eleven cases. Cancer 1982;49:188-197.

- 3 Clement PB: Selected miscellaneous ovarian lesions: small cell carcinomas, mesothelial lesions, mesenchymal and mixed neoplasms, and non-neoplastic lesions. Mod Pathol 2005;18(suppl 2):S113S129.

-4 Foulkes WD, Clarke BA, Hasselblatt M, Majewski J, Albrecht S, McCluggage WG: No small surprise small cell carcinoma of the ovary, hypercalcaemic type, is a malignant rhabdoid tumour. J Pathol 2014;233:209-214.

55 Karanian-Philippe M, Velasco V, Longy M, Floquet A, Arnould L, Coindre JM, Le Naoures-Mear C, Averous G, Guyon F, MacGrogan G, Croce S: SMARCA4 (BRG1) loss of expression is a useful marker for the diagnosis of ovarian small cell carcinoma of the hypercalcemic type (ovarian rhabdoid tumor): a comprehensive analysis of 116 rare gynecologic tumors, 9 soft tissue tumors, and 9 melanomas. Am J Surg Pathol 2015;39:1197-1205.

6 Scully R: Tumors of the Ovary and Maldeveloped Gonads. Washington, Armed Forces Institute of Pathology, 1979.

7 Kapoun M, Bouda J, Presl J, Vlasak P, Slunecko R: [Agressive small cell carcinoma of the ovary, hypercalcemic type, surgery and oncological treatment: case report]. Ceska Gynekol 2015;80:218-221.

-8 Zamecnik M, Michal M: Ovarian carcinoma of hypercalcemic type: myoid features and lack of estrogen and progesterone receptors. Virchows Arch 2003;442:186-187.

9 Beckwith JB, Palmer NF: Histopathology and prognosis of Wilms tumors: results from the First National Wilms' Tumor Study. Cancer 1978;41:1937-1948.

10 Araujo LH, Timmers C, Bell EH, Shilo K, Lammers PE, Zhao W, Natarajan TG, Miller CJ, Zhang J, Yilmaz AS, Liu T, Coombes K, Amann J, Carbone DP: Genomic characterization of non-small-cell lung cancer in African Americans by targeted massively parallel sequencing. J Clin Oncol 2015;33:1966-1973.

11 Strehl JD, Wachter DL, Fiedler J, Heimerl E, Beckmann MW, Hartmann A, Agaimy A: Pattern of SMARCB1 (INI1) and SMARCA4 (BRG1) in poorly differentiated endometrioid adenocarcinoma of the uterus: analysis of a series with emphasis on a novel SMARCA4-deficient dedifferentiated rhabdoid variant. Ann Diagn Pathol 2015;19:198-202.

12 Harrison ML, Hoskins P, du Bois A, Quinn M, Rustin GJ, Ledermann JA, Baron-Hay S, Friedlander ML: Small cell of the ovary, hypercalcemic type - analysis of combined experience and recommendation for management. A GCIG study. Gynecol Oncol 2006;100:233-238.

13 Powell JL, McAfee RD, McCoy RC, Shiro BS: Uterine and ovarian conservation in advanced small cell carcinoma of the ovary. Obstet Gynecol 1998;91:846-848.

14 Pautier P, Ribrag V, Duvillard P, Rey A, Elghissassi I, Sillet-Bach I, Kerbrat P, Mayer F, Lesoin A, Brun B, Crouet H, Barats JC, Morice P, Lhomme C: Results of a prospective dose-intensive regimen in 27 patients with small cell carcinoma of the ovary of the hypercalcemic type. Ann Oncol 2007;18:19851989.

-15 Tewari K, Brewer C, Cappuccini F, Macri C, Rogers LW, Berman ML: Advanced-stage small cell carcinoma of the ovary in pregnancy: long-term survival after surgical debulking and multiagent chemotherapy. Gynecol Oncol 1997;66:531-534. 


\section{Case Reports in Oncology}

\begin{tabular}{l|l}
\hline Case Rep Oncol 2016;9:305-311 \\
\hline $10.1159 / 000446694$ & $\begin{array}{l}\text { C 2016 The Author(s). Published by S. Karger AG, Basel } \\
\text { www.karger.com/cro }\end{array}$ \\
\hline
\end{tabular}

Kascak et al.: Small Cell Carcinoma of the Ovary (Hypercalcemic Type): Malignant Rhabdoid Tumor

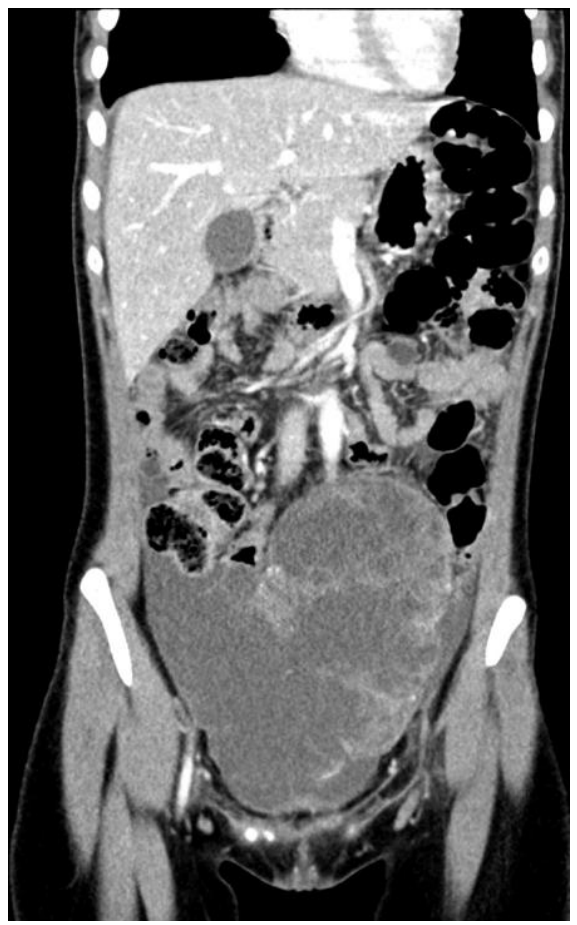

Fig. 1. Coronal CT scan before surgery.

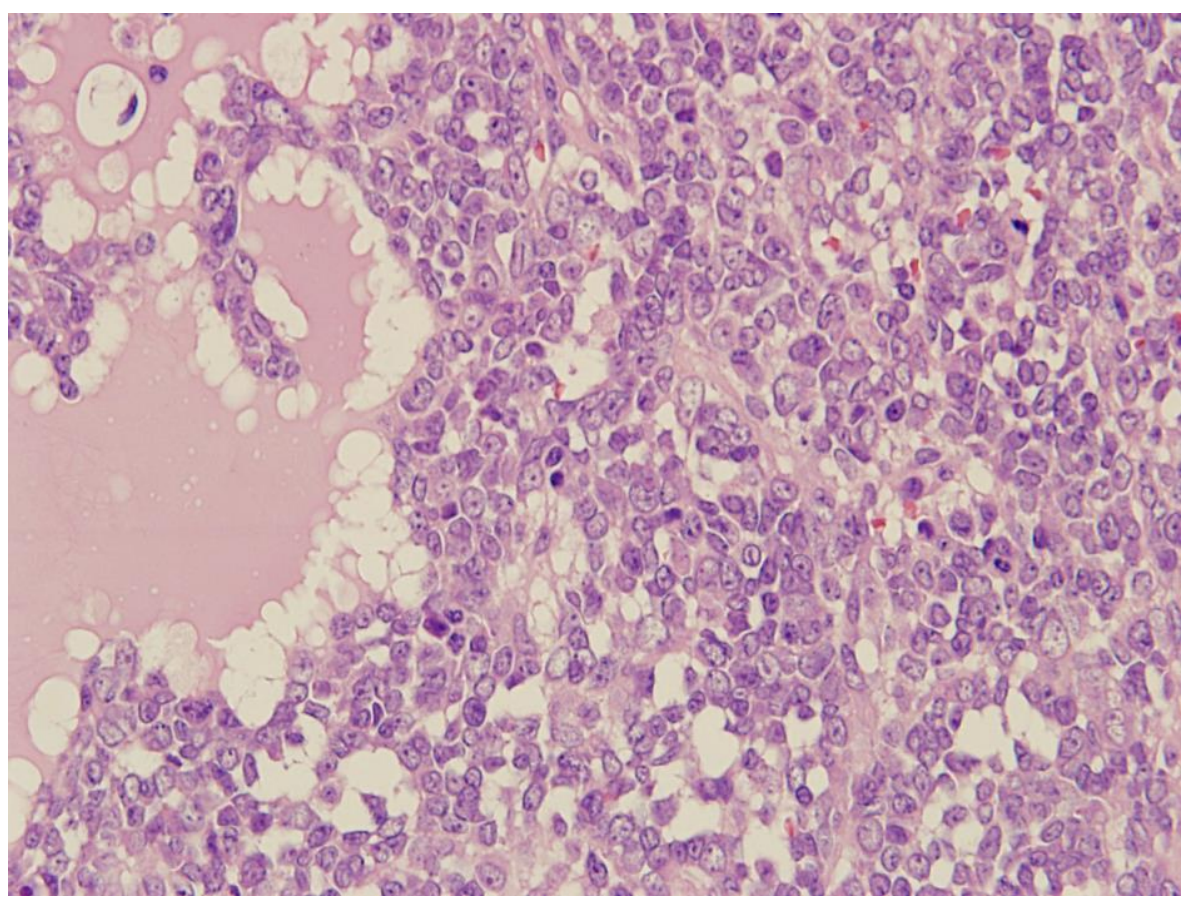

Fig. 2. Histological features of SCCOHT. Highly atypical small cells arranged in a solid pattern, with folliclelike space (left). Hematoxylin and eosin. $\times 400$. 


\section{Case Reports in Oncology}

www.karger.com/cro

Kascak et al:: Small Cell Carcinoma of the Ovary (Hypercalcemic Type): Malignant Rhabdoid Tumor

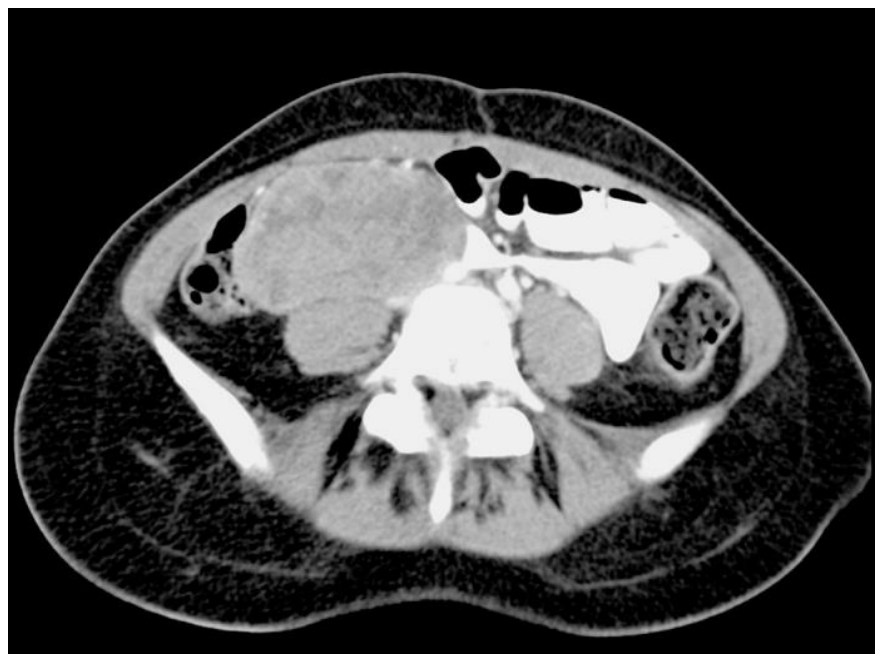

Fig. 3. Axial CT scan: relapse of disease 5 months after adjuvant chemotherapy. 